\section{DIGITAL COMMONS \\ @ UNIVERSITY OF SOUTH FLORIDA}

\section{ABO: Interactive Journal for Women in the Arts, 1640-1830}

\title{
"Side By Side With a Ruinous, Ever-Present Past": Trauma- Informed Teaching and the Eighteenth Century, Clarissa, and Fantomina
}

\author{
Kate Parker \\ University of Wisconsin - La Crosse, kparker@uwlax.edu \\ Bryan M. Kopp \\ University of Wisconsin La Crosse, bkopp@uwlax.edu \\ Lindsay Steiner \\ University of Wisconsin La Crosse, Isteiner@uwlax.edu
}

Follow this and additional works at: https://digitalcommons.usf.edu/abo

Part of the Educational Methods Commons, Feminist, Gender, and Sexuality Studies Commons, Liberal Studies Commons, Literature in English, British Isles Commons, and the Scholarship of Teaching and Learning Commons

\section{Recommended Citation \\ Parker, Kate; Kopp, Bryan M.; and Steiner, Lindsay (2021) "'Side By Side With a Ruinous, Ever-Present Past": Trauma-Informed Teaching and the Eighteenth Century, Clarissa, and Fantomina," ABO: Interactive Journal for Women in the Arts, 1640-1830: Vol.11: Iss.1, Article 5. \\ http://doi.org/10.5038/2157-7129.11.1.1236 \\ Available at: https://digitalcommons.usf.edu/abo/vol11/iss1/5}

This Pedagogy is brought to you for free and open access by Digital Commons @ University of South Florida. It has been accepted for inclusion in ABO: Interactive Journal for Women in the Arts, 1640-1830 by an authorized administrator of Digital Commons @ University of South Florida. For more information, please contact digitalcommons@usf.edu. 


\title{
"Side By Side With a Ruinous, Ever-Present Past": Trauma-Informed Teaching and the Eighteenth Century, Clarissa, and Fantomina
}

\begin{abstract}
This article explores the need for and applications of trauma-informed teaching in eighteenth-century studies, particularly around representations of sexual trauma (rape) and consent. The prevalence of trauma guarantees its presence in our classrooms, even and especially in its absences. As the field of eighteenth-century studies continues to reframe its white, Eurocentric, male-dominated past through more intentionally inclusive research and teaching methods, particularly those that explore the intersections of eighteenth-century studies and social justice approaches to education, the presence of trauma in our classrooms will become only more significant. Keeping in mind those students of marginalized identities who are most likely to be impacted by trauma--those who identify as womxn, students of color, trans, LGBTQ+, Black, Latinx, Native, Indigenous, lower-income and first-generation--we detail strategies for support and for developing a trauma-informed classroom atmosphere that will best support all students in their learning.
\end{abstract}

\section{Keywords}

eighteenth-century, trauma-informed teaching, trauma, sexual trauma, rape, representation, pedagogy, social justice, social justice education, Samuel Richardson, Clarissa, Eliza Haywood, Fantomina, Seo-

Young Chu, teaching

\section{Creative Commons License}

cc) (i) (8)

This work is licensed under a Creative Commons Attribution-Noncommercial 4.0 License 
The essence of trauma is that it is overwhelming, unbelievable, and unbearable. Each patient demands that we suspend our sense of what is normal and accept that we are dealing with a dual reality: the reality of a relatively secure and predictable present that lives side by side with a ruinous, ever-present past. -Bessel van der Kolk, The Body Keeps the Score (35)

In November of 2017, Seo-Young Chu, an associate professor of English at Queens College published a stunning, meditative, and heart-wrenching essay in Entropy magazine about her experiences of sexual harassment and assault while a graduate student at Stanford University. Her essay rapidly circulated among eighteenth-century scholars, as she named her rapist: Jay Fliegelman - a looming figure in early American studies at Stanford and a widely-respected teacher after whom the American Society for Eighteenth-Century Studies Graduate Caucus had recently named its annual mentoring award. In "WOVEN: A Refuge for Jae-In Doe: Fugues in the Key of English Major," Chu details her experience of being simultaneously abused and mentored by Fliegelman, and the post-assault fallout. "It - his voice - it accompanies mine like an accent," she says. Stringing together adaptations of canonical poetry one might study in a literature classroom (sonnets by Shakespeare, Spenser, Donne, Milton and Shelley, and Marvell's “The Garden"), Chu weaves her victimization through variations and repetitions of traumatic rhythms: "His ghost stands watching me while I'm asleep. / I know this cannot be real because / I'm wide awake. I never fall asleep." An aching for untethered expression resounds in this story of rape recast within patriarchal language, which also reflects more particularly, and pointedly, the interests of her advisor, whose 1982 book Prodigals and Pilgrims explored the revolutionary response to colonial, "patriarchal" rhetorics. Throughout Chu's piece, the teaching, the trauma, and the post-traumatic stress become inextricable: what she has learned, in Fliegelman's classroom, his assigned readings, his office, is her trauma. Part of what makes reading Chu's essay so troublesome for those of us in eighteenth-century studies is that we find ourselves directly implicated in the celebration of the "excellent" teaching that ultimately served as a guise for her, and others', victimization.

While this case is by no means unusual - both in the crime committed and the tiny penalty Fliegelman received, which amounted to a mere blip in an otherwise storied career - it is thankfully not the norm that students are traumatized by their professors (Liu). And yet our classrooms are by no means trauma-free zones. By the time they reach college, $66 \%$ to $85 \%$ of youth will report lifetime traumatic event exposure, with many reporting multiple exposures. As many as 50 percent 
of college students are exposed to a potentially traumatizing event in their first year of college (Davidson 5). Trauma disproportionately affects marginalized populations of students: those who identify as womxn, students of color, trans, LGBTQ+, Black, Latinx, Native, Indigenous, as well as lower-income and firstgeneration students (Davidson 9-12). The prevalence of trauma guarantees its presence in our classrooms, even and especially in its absences, both in the unspoken experiences of our students and the hesitance to directly engage trauma in readings and discussions. Acknowledged or not, students at our regional comprehensive university, as well as elsewhere, read their own traumas through and into the texts we assign in class. Texts that may seem innocuous to faculty can evoke powerful affective and/or somatic responses from trauma victims, and it is both reasonable and humane for faculty to actively anticipate "negative emotions" around any text (Hanlon). Indeed, traumatized students cannot learn; it is physiologically impossible for a brain under siege to properly intake and process new information (van der Kolk 70-71). A trauma-responsive classroom is one that maximizes the possibility that all students will feel safe enough to commit to doing the rigorous intellectual and emotional work required in reading eighteenth-century texts. As the field of eighteenth-century studies continues to reframe its white, Eurocentric, male-dominated past through more intentionally inclusive research and teaching methods, particularly those that explore the intersections of eighteenth-century studies and social justice approaches to education, ${ }^{1}$ the presence of trauma in our classrooms will become only more visible - both in the experiences of the diverse students we wish to attract to our classes, and in the content we teach.

The trauma-informed classroom is thus rooted in principles of a safe environment, recognition of students' authentic experiences, resilience and growth mindset, and support-seeking. While there are inherent challenges to trauma-informed teaching (e.g. the need for instructors to be aware of and proactive in setting compassionate and transparent boundaries), it can, when properly implemented, enable community-building, promote equity, acknowledge multiple, intersectional identities among our students, and cultivate a healthy environment of trust, challenge, and risk-taking. Given these goals, which are framed by twenty-firstcentury pedagogies of feminism and activism, it may seem surprising to some that we find eighteenth-century texts like Samuel Richardson's Clarissa (1748) and Eliza Haywood's Fantomina (1725) to be such invaluable teaching tools. And yet it is the figurative (and to students archaic, even oblique) ways these novels engage traumatic events - particularly, sexual trauma but also other forms-while simultaneously centering subjective experiences that makes them so relevant to students experiencing trauma and suffering. 
As Bessel van der Kolk describes it, trauma "by definition, is unbearable and intolerable," and those who experience trauma find it often a representational black hole (1). Chu calls it "blank space" in her testimony: trauma as the persistent and spontaneous absence of language. Students who encounter the moment of Clarissa's rape at the hands of Lovelace note, as many scholars have, its brevity and force: "The affair is over. Clarissa lives." In The Rape of Clarissa, Terry Eagleton writes of this moment:

The 'real' of Clarissa - the point around which this elaborate two thousand page text pivots - is the rape; yet the rape goes wholly unrepresented, as the hole at the centre of the novel towards which this huge mass of writing is sucked only to sheer off again . . .Lovelace's sexual climax is also the novel's great anticlimax, a purely impersonal act of violence which refuses entry into discourse and brusquely unveils language for what it is: a ceaselessly digressive supplement which, pace Richardson's own ideology of the sign, will never succeed in nailing down the real. . . . The violated body of Clarissa slips through the net of writing to baffle representation. (61-62)

Putting aside the disturbing slippages Eagleton makes (e.g., between rape as "act of violence" and "sexual climax"), this characterization of trauma's nonsignification-Richardson's portrayal of rape as a gravitational "hole at the centre of the novel" - accurately depicts what neuroscience tells us about representation, trauma, and post-traumatic stress disorder. ${ }^{2}$ The rape, given only five words in a novel of nearly a million words, is the text's most significant moment, the "hole" around which all its pages swirl. And yet it is itself unspeakable, defying language and representation. Students who have experienced trauma may relate to this moment in a very visceral way; every moment of their life has been punctuated and is now structured by the traumatic experience that sits at the very core of who they are, but the trauma itself often cannot be engaged directly without tremendous will and difficulty. Richardson's preference for the implicit where penetrative rape is concerned (perhaps inadvertently) reinforces the kind of unspeakable silence imposed by the traumatic moment. Even students inexperienced with trauma can engage this moment conceptually: in this dizzying, compulsive world of signifiers, a daily life once structured around stable meaning is now punctuated by a representational "hole" with the power to "suck" in the "huge mass of writing," inflecting absolutely everything.

Yet this absence can make it easy for those who are not trauma-informed to unwittingly transform the unspeakable into the silenced. The inherent difficulty of speaking or representing trauma in the text need not be a refusal to acknowledge 
the trauma that is in the classroom room and can, in fact, present an opportunity to examine the stakes of both silence and speaking. A trauma-informed classroom provides the support, and the necessary pause, that allows students to grapple with experiences like Clarissa's symbolically, affectively, and empathetically: to see her, in other words, not just as a character in a novel but as a trauma survivor desperate to shape and give substance to her own experiences. When paired with Lovelace's brief, perfunctory missive (Letter 257, pg. 883) Clarissa's torn papers, included in Lovelace's letter to Belford (Letter 261, pp. 890-93) in which she famously tries to make sense of what has happened to her, can prove effective and compassionate teaching tools (in addition to being easily excerpted from the modernized Penguin edition, taking approximately 5 of its 1499 pages). Students engaging with these two scenes contrast Lovelace's cruel brevity with Clarissa's convoluted expressions, noting their polyvocality, their randomness and their irrationality. Even students confused or frustrated by the obscure, allusive language recognize that Clarissa is faced with an impossible task: she must find language for the incomprehensible act that has rendered her "no longer what I was in any one thing" (890). Working with these torn drafts and prompted by critical discussion questions that place these fragments more generally into conversations about how we, as readers, tend to approach accounts of rape or attempted rapeperhaps referencing contemporary examples like Anita Hill or Christine Blasey Ford-students begin to explore the complexities of piecing together language around trauma. And, further, if paired with neuroscientific research on posttraumatic stress-induced alexithymia (van der Kolk 100-01) or the deactivation of the dorsolateral prefrontal cortex - the brain's “timekeeper" (van der Kolk 69) students can begin to draw powerful connections between the novel's central event, its post-traumatic symptomologies, and the often hostile contexts of a contemporary rape culture, which is evinced in the anticipated and actual responses of Clarissa's family and friends, and, as many scholars have noted, in the institutionalized sexism that permeates that novel.

An excellent resource for any discussion of Lovelace's rape of Clarissa is Kathleen Lubey's brilliant article, "Sexual Remembrance in Clarissa." Lubey argues persuasively that "penetrative rape" is "only . . the most violent manifestation of a systematic instrumentalization of women's bodies upon which eighteenth-century social institutions depended" (151). Students familiar with twenty-first-century rape culture will recognize — and find resonances withLubey's arguments here, as Clarissa's rape is the cumulative result of a heterosexist culture that "operationalizes women's bodies" rather than a single act of violation at the hands of a frustrated suitor (151). Placing Richardson in this larger context is extremely effective in the trauma-informed classroom because it underscores the structural, institutional nature of systemic violence - rather than 
its interpersonal dimensions - in both the eighteenth century and today. Additionally, by situating rape culture more globally within a heterosexist, racist system - perhaps by pairing Lubey with Ibram X. Kendi's provocative book How to be an Anti-Racist (2019), especially the chapter on "Gender"-students are able to see the interwoven nature of systemic violence, which amplifies the experiences of marginalized students more broadly. However, given this larger context of structural violence, students or professors not informed by trauma and its psychological and representational dynamics may elide or inadvertently romanticize the moments most salient for trauma survivors and in so doing participate in a process of retraumatization.

Unless heavily excerpted, Clarissa - its length, complexity, and difficulty - is only suited to an advanced seminar at a regional comprehensive institution like ours; more regularly, introductory or general education courses will engage shorter texts like Haywood's Fantomina. While, again, not a sexually explicit text, students are quite quickly resistant to its gendered paradigm of sexual performance and play, which clearly privileges the male suitor and facilitates, rather swiftly, Fantomina's rape at the hands of Beauplaisir; within the space of approximately six pages in a modern edition, readers move from an empowered, self-actualized Fantomina "having at that Time no other Aim, than the Gratification of an innocent Curiosity" to her sexual assault: "In fine, she was undone; and he gain'd a Victory, so highly rapturous, that had he known over whom, scarce could he have triumphed more" $(42,46)$. At the outset, students are likely to criticize Fantomina's behavior: "What did she expect would happen?" is commonly voiced. This question mirrors the kinds of interrogations usually put to rape survivors regarding behavior, clothing, etc. at the time of assault. Issues like rape and consent ("she asked for it, because she was dressed a certain way") resonate with other sorts of complicated responses to the story's "blurred lines," as Emily Dowd-Arrow and Sarah R. Creel have described elsewhere (3). Rather than immediately offer historical correctives, a trauma-informed teacher might press at the heart of such resonances - these issues face women in the twenty-first century, too.

As a rape victim and as an eighteenth-century woman, Fantomina's ability to sexually self-express is seriously compromised as the narrative progresses and certainly by its end. Haywood's story is often read as a prescient nod to gender performativity because it places at its center a heroine who constantly recreates herself and performs various gender roles in order to fully express her desires and achieve a committed relationship with her inconstant lover. Fantomina's performance of gender seems to reflect the gendered nature of female authorship in the eighteenth century: Haywood (and other women authors), like the characters they pen, are "literal nobodies" (Gallagher xiii). But a trauma-informed 
perspective on her behavior could read the narrative as compulsive, a constant, fitful recreation of her original trauma in an effort to make sense of it, to reframe as love what was a violent act of power and control: " $\mathrm{He}$ was bold; - - he was resolute; She fearful,_- confus'd, altogether unprepar'd to resist in such Encounters, and rendered more so, by the extreme Liking she had to him" (Haywood 46). And though we are told she behaves with "unquestionable Authority over herself" as she seems to lead Beauplaisir through lascivious encounter after lascivious encounter, her ultimate aim is to regain his respect and rewrite her traumatic past: for her "fugitive Lover" to return "the Height of Transport she enjoyed when the agreeable Beauplaisir kneel'd at her Feet, imploring her first Favours ..." $(68,51)$. Throughout the text, the language associated with Beauplaisir is forceful, controlling and manipulative (he "compel[s]" her to sit as the servant Celia) and yet Fantomina persists in trying to make the "TRAYTOR!" into "an agreeable person" who will remain constant to her $(53,59)$. Her most pleasurable encounter is the one in which she is able to reclaim some agency and control; as Incognita, she preserves "the Ardour, which alone makes Love a Blessing" by fleeing him immediately after sex "with too much Swiftness for him to have overtaken her, if he had attempted it" $(65,67)$. Beauplaisir clearly remains the predator and Fantomina the victim, but she has found a way - suggestively, by darkening, or erasing, both her body and her boudoir - to create a "Snare" that gives "no Cause [for men] to scorn our easy, weeping, wailing sex!" (65). Fantomina, in other words, does not escape rape culture; as a victim of sexual violence, she internalizes its inevitability and compulsively recreates it until she can develop a limited agency within it. Sexual impulsivity and increased dysregulation - including the propensity to take larger and larger sexual risks - is a known symptom of PTSD, as is deliberate self-harm (Tull et al 803). Students are then confronted with a problem that is equally endemic in twenty-first-century rape culture: is this the behavior of a sexually emancipated woman? Or is this the compulsive, harmful risk-taking of a sexually traumatized victim?

Students may find themselves caught between recognition of unexpected relevance and condemnation from the moral high ground. When teaching historical literatures - especially to non-majors - we may find that students disengage by assuming a presentist stance: what Lynn Hunt has called a "kind of moral complacency and self-congratulation" ("Against Presentism"). Students encountering Haywood's Fantomina or amatory works by other early modern women authors for the first time are likely to first adopt this sort of stance, in which they celebrate contemporary "liberated" ideas about sexuality and dismiss "archaic" representations of nonconsensual sex as simply evidence that confirms the eighteenth century as a less-progressive moment in the history of gender 
relations. Often, however, there are quiet stirrings of horrified recognition, as some students see themselves, and their own nonconsensual ${ }^{3}$ encounters (even those that do not register as sexual harassment, assault, or rape) echoed in these texts. And for these students - arguably, for all students, but certainly for those we have witnessed at a regional comprehensive institution - the difficulty of acknowledging and engaging these undercurrents must be weighed against the risks of (publicly) doing so in the classroom. When we as teachers become more aware that trauma lives within our classrooms - there is no question it that it exists, only whether we will acknowledge it, and in what ways - we must contend with how to support our students through the inevitable emotions that come from recognizing the injustices of a world that was, and continues to be, systematically sexist, racist, homophobic, and otherwise biased. Fantomina-haters may suddenly become Fantomina-defenders, but the question of how best to offer necessary support and resources within and beyond the classroom remains.

Faculty are by no means immune to the complicity that may be felt by students because teachers, after all, set the curriculum. "Why are you making me read this novel about trauma?", a student may well ask. Furthermore, "why are you inviting my peers to repeat these same uninformed, at times cruel, responses?" The institutional context within which we encounter students and they encounter the novels we assign can serve to intensify the effects of trauma or to provide support for trauma survivors, or both simultaneously. Typically selected by instructors without explicit consent from their students, course content is intended to engage, or provoke; discussions and assignments may likewise structure behaviors and interactions without student input. While one may argue that students grant consent by registering for the course and, as adults, remain free to leave, they may nonetheless in the middle of a book or discussion find themselves saying, "I did not sign up for this." Fear of this moment may be one reason instructors shy away from talking about trauma at all, but not talking may be akin to refusing to talk, turning a blind eye, and even tacitly condoning.

Preparing students for readings, conversations, and assignments that intersect with the complex, lived experiences of trauma is a key support strategy. Before class begins, in the syllabus itself, a trauma-informed professor may describe, with complete transparency, the work of the class, why texts were chosen, the conversations that will be had, the possibility that we may become uncomfortable at times, indeed, unpredictably shaken, and that we are neither alone nor without support at any moment because trauma is widely experienced and resources exist. While trauma may not be the rule, it is certainly no exception, and thus professors may expect that one or more students may be experiencing traumas past or present before, during, or after any class period. For this reason, a classroom climate may be cultivated that allows students to freely enter and leave the 
physical, institutional space with the established knowledge that the instructor will follow up with offers of support. Course policies may have built-in flexibility to allow for accommodations as needs present themselves. Such early interventions may include trigger warnings about certain texts and activities, but they extend far beyond them to normalize the experience and recognize the ubiquity of trauma itself.

A trauma-informed approach seeks to foster a classroom atmosphere that raises awareness of the presence of trauma, that promotes help-seeking and self-care behaviors, and that holds space for difficult conversations and unexpected resonances. Needless to say, student perspectives will vary and instructors may find themselves in a balancing act. How do we support trauma survivors while at the same time educating those who have not (yet) experienced it or those who may hold outright misconceptions? The work of advocacy overlaps with, but is not the same as, providing support. The following examples are worth keeping in mind because they paint the challenge starkly. To start, some students may have experienced a traumatic episode only to find themselves in class the very same day seeking normalcy. Or, they may be reliving past traumas as they struggle to sit still, concentrate, and learn. Others may experience the intersection of powerful institutional dynamics that reinforce structural oppression alongside course content; those who suffer from PTSD, for example, may bear the brunt of blanket attendance policies or stated or unstated rules against leaving the classroom during lecture. Carefully chosen content may re-traumatize survivors despite hopes that it might empower them. And other students may be entirely apathetic, unaffected, and unaware of these surging undercurrents, which proves additionally complicated for a survivor navigating class discussion and group work, not to mention for a faculty member facilitating these discussions. What is perhaps most compelling about these scenarios is that they are unfolding regardless of whether we embrace the challenges - and the opportunities - they present.

We conclude with a framework for trauma-informed pedagogy (see coda) that not only recognizes the impact of traumatic events, triggers, and stressors on students, but actively works to promote safety, provide relevant school and community resources, and assist students in managing distress in a predictable, inclusive environment. When doing such work, we are left with reassurances: this is what literature is supposed to do; it is supposed to show us to ourselves, and to show others to $u s$, so that we can move forward from the text with an increased understanding and compassion for all beings - including, of course, ourselves. Here, Chu's essay - in its meditations on the intersections of canonical, patriarchal literature and embodied trauma - comes to life for students. The real work of support comes from acknowledging that it is not simply a trigger warning 
that is needed but also a commitment to creating a safe space in which students can encounter unsafe things, and to walk away from these encounters feeling that they are in community, not in isolation. This is a commitment to students' lives and experiences, and it is one that is made possible by a classroom that acknowledges, engages, and supports trauma as a viable and common human experience - not simply in prevalence, but in the sense of being in common, sharing experiences with other humans in and outside of the classroom and, indeed, throughout history.

\section{Coda: Trauma-informed teaching ${ }^{4}$}

In times of crisis, we are more aware than ever before of the kinds of traumas students are regularly experiencing outside of the classroom: community violence, domestic violence, sex trafficking, serious and chronic medical conditions, natural disasters, neglect, physical abuse, displacement and refugee trauma, school violence, sexual abuse, terrorism, loss of a loved one/traumatic grief, etc. The model of trauma-informed care is rooted in key principles of safe environment, belief, resilience, and support.

\section{Course Design Considerations}

Faculty seeking to meet the needs of students who have experienced trauma can design courses that:

1. connect students to the school community, including available campus and community resources and available supports, such as mental health counseling and emergency resources;

2. provide students with opportunities to practice and reinforce healthy coping skills (for example, in self-reflection or in growth mindset);

3. embrace teamwork and shared leadership, which empowers and encourages all students to contribute;

4. anticipate and adapt to the changing needs of the students and the community by practicing responsive pedagogy, being flexible and inclusive with course content, and building alternative learning experiences into the lesson plan to support students who may be retraumatized or triggered by particular content.

\section{Classroom Policy Considerations}

Trauma-informed pedagogy requires faculty to be transparent, flexible, consistent and compassionate in relationships with students and in the policies that inform those relationships. Course syllabi and assignments should be reviewed with the following questions, in order: 
- What formal policies (including grading rubrics, etc.) are in place here? What kinds of relationships do these build with learners (i.e., punitive, welcoming, etc.)?

- What kinds of external, institutional, and/or personal limits are in place for the instructor? What policies is the instructor free and willing to redefine or renegotiate?

- How can instructors clearly, compassionately, and consistently communicate the expectations of non-negotiable policies?

- Which policies may be further developed, adjusted, or revised to improve flexibility to support all learners, including those who have been traumatized?

- What informal policies and norms may affect student-student and studentteacher interactions in class discussions and group work? What issues may arise and be anticipated?

\section{Trauma-Informed Strategies}

1. Give trigger warnings for content that may affect student feelings of safety.

2. Be familiar with and prepared to make referrals to appropriate campus or local support services. Have a "cheat sheet" that reminds you of what's available on campus and in the community.

3. Give choices for participation in class activities.

4. Give alternative assignments for students who need accommodations.

5. Check in with students who are exhibiting signs of trauma. (See "Trauma-Informed Teaching" website to recognize signs of trauma in your students.)

6. Acknowledge current events that could be triggering or affect feelings of safety for students.

7. Be inclusive when discussing topics related to identity, relationships, family, and home.

8. Avoid romanticizing — or problematize the romanticization oftrauma narratives.

9. Model positive relationships.

10. Ask questions and listen to students instead of making assumptions (don't assume students experiencing trauma are bad students). Ask first: "what has happened to you?" rather than "what's wrong with you?" or "why didn't you...?"

11. Normalize and validate feelings that come from experiencing trauma. Normalize help-seeking. 
12. Maintain high, consistent expectations even when making accommodations (make clear where there is and is not flexibility; acknowledge limits and hard lines).

13. Be transparent about your role and what you can/cannot do by maintaining appropriate boundaries. (Teachers are not counselors; we are not experts on students' feelings.)

14. Be trustworthy and reliable to help build trust with students over time (but don't expect instant trust).

15. Think about the cultural references and examples you use in class and how they may be triggering to students.

\footnotetext{
${ }^{1}$ Recent examples of such work include Emily Dowd-Arrow and Sarah R. Creel's article "“I Know You Want It': Teaching the Blurred Lines of Eighteenth-Century Rape Culture" (ABO: Interactive Journal for Women in the Arts, 1640-1830, vol. 6, no. 2 [ Fall 2016]); contributions by Shari Evans and Wanda Creaser to the 2009 volume Teaching the Eighteenth Century (edited by Mary Ann Rooks; Cambridge Scholars Publishing); and many contributions to recent $M L A$ Approaches to Teaching Series focused on eighteenth-century women authors, including Leslie Richardson's article on teaching Oroonoko at a HBCU in Approaches to Teaching Behn's Oroonoko (eds. Cynthia Richards and Mary Ann O'Donnell, 2013) and the just-published Approaches to Teaching the Works of Eliza Haywood (ed. Tiffany Potter, 2020) which includes many articles framing Haywood within contemporary sexuality studies.

${ }^{2}$ See Chapter 3 of van der Kolk's The Body Keeps the Score, "Looking into the Brain: The Neuroscience Revolution" (39-47).

${ }^{3}$ We use this more inclusive term after the work of Lynn Phillips, whose book Flirting with Danger: Young Women's Reflections on Sexuality and Domination (NYU Press, 2000) shows that young women often experience sexual encounters that meet the legal definition of rape without labeling that experience as such.

${ }^{4}$ The material presented here is available in more detail on our website: "Trauma Informed Teaching. The University of Wisconsin-La Crosse Center for Advancing Teaching and Learning (CATL) Teaching Improvement Guide. https://www.uwlax.edu/catl/guides/teaching-improvementguide/trauma-informed/. Accessed 13 June 2020.
} 


\section{Works Cited}

Chu, Seo-Young. "WOVEN: A Refuge for Jae-In Doe: Fugues in the Key of English Major.” Entropy, 3 Nov. 2017. https://entropymag.org/a-refugefor-jae-in-doe-fugues-in-the-key-of-english-major/. Accessed 15 May 2020.

Davidson, Shannon. Trauma-Informed Practices for Postsecondary Education: A Guide. Education Northwest, 2017.

Dowd-Arrow, Emily and Sarah R. Creel. "'I Know You Want It': Teaching the Blurred Lines of Eighteenth-Century Rape Culture." ABO: Interactive Journal for Women in the Arts, 1640-1830, vol. 6, no. 2 (Fall 2016). http://dx.doi.org/10.5038/2157-7129.6.2.2.

Eagleton, Terry. The Rape of Clarissa: Writing, Sexuality and Class Struggle in Samuel Richardson. University of Minnesota Press, 1982.

Gallagher, Catherine. Nobody's Story: The Vanishing Acts of Women Writers in the Marketplace, 1670-1920. University of California Press, 1995.

Hanlon, Aaron. "The Trigger Warning Myth.” The New Republic. 14 Aug. 2015. https://newrepublic.com/article/122543/trigger-warning-myth. Accessed 13 June 2020.

Haywood, Eliza. Fantomina and Other Works. Eds. Alexander Pettit, Margaret Case Croskery, and Anna C. Patchias. Broadview Press, 2004.

Hunt, Lynn. “Against Presentism.” Perspectives on History. May 2002. https://www.historians.org/publications-and-directories/perspectives-onhistory/may-2002/against-presentism. Accessed 15 May 2020.

Kendi, Ibram X. How to Be An Antiracist. Penguin Random House, 2019.

Kopp, Bryan, Kate Parker, and Lindsay Steiner. "Trauma-Informed Teaching." The University of Wisconsin-La Crosse Center for Advancing Teaching and Learning (CATL) Teaching Improvement Guide. https://www.uwlax.edu/catl/teaching-guides/teaching-improvementguide/trauma-informed/. Accessed 13 June 2020.

Liu, Fangzhou. "Behind the Fliegelman Sexual Misconduct Investigation." The Stanford Daily. 2 Dec. 2017. 
https://www.stanforddaily.com/2017/12/02/behind-the-fliegelman-sexualmisconduct-investigation/. Accessed 5 May 2020.

Lubey, Kathleen. "Sexual Remembrance in Clarissa." Eighteenth-Century Fiction, vol. 29, no. 2 (Winter 2016-17): 151-78.

Richardson, Samuel. Clarissa, or, The History of a Young Lady, edited by Angus Ross, Penguin, 1985.

Tull, Matthew T., Nicole H. Weiss, and Michael J. McDermott. "Post-Traumatic Stress Disorder and Impulsive and Risky Behavior: Overview and Discussion of Potential Mechanisms." Comprehensive Guide to PostTraumatic Stress Disorders, edited by Colin R. Martin, Victor R. Preedy, and Vinood B. Patel, Springer, 2016, pp. 803-16.

van der Kolk, Bessel. The Body Keeps the Score: Brain, Mind, and Body in the Healing of Trauma. Penguin, 2014. 